\title{
Protocol for a multi-centered, stepped wedge, cluster randomized controlled trial of the de-adoption of oral chlorhexidine prophylaxis and implementation of an oral care bundle for mechanically ventilated critically ill patients: the CHORAL study
}

Craig M. Dale ${ }^{1,2,3}$, Louise Rose ${ }^{4,5,1,3}$, Sarah Carbone ${ }^{1}$, Orla M. Smith ${ }^{6,7,1}$, Lisa Burry ${ }^{8,9,10}$, Eddy Fan ${ }^{10,11}$, Andre Carlos Kajdacsy-Balla Amaral ${ }^{4,10,3}$, Victoria A. McCredie ${ }^{10,11}$, Ruxandra Pinto ${ }^{4}$, Carlos R. Quiñonez ${ }^{12}$, Susan Sutherland ${ }^{13}$, Damon C. Scales ${ }^{4,10,3}$ and Brian H. Cuthbertson , $^{40,3^{*}}$

\begin{abstract}
Background: Routine application of chlorhexidine oral rinse is recommended to reduce risk of ventilator-associated pneumonia (VAP) in mechanically ventilated patients. Recent reappraisal of the evidence from two meta-analyses suggests chlorhexidine may cause excess mortality in non-cardiac surgery patients and does not reduce VAP. Mechanisms for possible excess mortality are unclear. The CHORAL study will evaluate the impact of de-adopting chlorhexidine and implementing an oral care bundle (excluding chlorhexidine) on mortality, infection-related ventilator-associated complications (IVACs), and oral health status.
\end{abstract}

Methods: The CHORAL study is a stepped wedge, cluster randomized controlled trial in six academic intensive care units (ICUs) in Toronto, Canada. Clusters (ICU) will be randomly allocated to six sequential steps over a 14-month period to de-adopt oral chlorhexidine and implement a standardized oral care bundle (oral assessment, tooth brushing, moisturization, and secretion removal). On study commencement, all clusters begin with a control period in which the standard of care is oral chlorhexidine. Clusters then begin crossover from control to intervention every 2 months according to the randomization schedule. Participants include all mechanically ventilated adults eligible to receive the standardized oral care bundle. The primary outcome is ICU mortality; secondary outcomes are IVACs and oral health status. We will determine demographics, antibiotic usage, mortality, and IVAC rates from a validated local ICU clinical registry. With six clusters and 50 ventilated patients on average each month per cluster, we estimate that 4200 patients provide $80 \%$ power after accounting for intracluster correlation to detect an absolute reduction in mortality of $5.5 \%$. We will analyze our primary outcome of mortality using a generalized linear mixed model adjusting for time to account for secular trends. We will conduct a process evaluation to determine intervention fidelity and to inform interpretation of the trial results.

(Continued on next page)

\footnotetext{
* Correspondence: Brian.Cuthbertson@sunnybrook.ca

${ }^{4}$ Department of Critical Care Medicine, Sunnybrook Health Sciences Centre,

Toronto, Canada

${ }^{10}$ Interdepartmental Division of Critical Care Medicine, University of Toronto,

Toronto, Canada

Full list of author information is available at the end of the article
}

(c) The Author(s). 2019 Open Access This article is distributed under the terms of the Creative Commons Attribution 4.0 International License (http://creativecommons.org/licenses/by/4.0/), which permits unrestricted use, distribution, and reproduction in any medium, provided you give appropriate credit to the original author(s) and the source, provide a link to the Creative Commons license, and indicate if changes were made. The Creative Commons Public Domain Dedication waiver (http://creativecommons.org/publicdomain/zero/1.0/) applies to the data made available in this article, unless otherwise stated. 
(Continued from previous page)

Discussion: The CHORAL study will inform understanding of the effectiveness of de-adoption of oral chlorhexidine and implementation of a standardized oral care bundle for decreasing ICU mortality and IVAC rates while improving oral health status. Our process evaluation will inform clinicians and decision makers about intervention delivery to support future de-adoption if justified by trial results.

Trial registration: ClinicalTrials.gov, NCT03382730. Registered on December 26, 2017.

Keywords: Chlorhexidine, Critical care, Ventilator-associated pneumonia, Oral care, Stepped-wedge cluster randomized controlled trial, Process evaluation, Mechanical ventilation

\section{Background}

Ventilator-associated pneumonia (VAP) was previously considered to have high morbidity and mortality and was the target for prevention strategies [1]. Evidence-based guidelines encouraged ICUs to adopt "ventilator bundles", including the application of chlorhexidine gluconate mouth rinse, to prevent VAP [2-4]. However, two updated meta-analyses suggest chlorhexidine may cause excess mortality in some critically ill patients whilst failing to prevent VAP $[5,6]$. Moreover, recent analyses demonstrate that the attributable mortality for VAP is low (1\%) [7]. In combination, these data have placed guidelines for the use of oral care with chlorhexidine into question.

A variety of mechanisms have been proposed for the lack of effect of chlorhexidine oral rinse on VAP [8-11]. However, the biological mechanism for chlorhexidine causing excess mortality is less clear. Chlorhexidine could be directly toxic or it may trigger hypersensitivity reactions contributing to erosive mucosal lesions, predisposing patients to infection and respiratory failure [12, 13]. The additional burden of such complications in critically ill patients could negatively impact mortality.

Safe and effective oral care plays a critical role in the oral and systemic health outcomes of millions of people admitted to intensive care units (ICUs) worldwide each year for invasive mechanical ventilation [14]. Inadequate salivary flow associated with critical illness and oral intubation cause oral health dysfunction, including abnormal oropharyngeal colonization with bacteria $[15,16]$. Aspiration of this abnormal oral bacteria leads to infection-related ventilator-associated complications (IVACs), which ultimately increase the duration of mechanical ventilation and costs of treatment [17]. Furthermore, resultant xerostomia is associated with severe pain and discomfort [18, 19].

With evidence for a lack of benefit in VAP prevention, as well as possible harm, immediate discontinuation of oral chlorhexidine in the ICU is a possible solution. However, the lack of a clear mechanism for harm, low to moderate quality of the evidence contributing to recent metaanalyses, and the potential for unintended consequences of rapid and widespread de-adoption all necessitate evaluation through scientifically rigorous de-adoption [20]. Therefore, we will conduct a multi-centered, stepped wedge, cluster randomized controlled trial (SW-CRT) of the de-adoption of oral chlorhexidine and implementation of a standardized oral care bundle in critically ill patients undergoing mechanical ventilation with an embedded process evaluation.

\section{Research questions}

1. What are the effects of the de-adoption of oral chlorhexidine and introduction of a standardized oral care bundle on mortality in mechanically ventilated critically ill adults?

2. What are the effects of the de-adoption of oral chlorhexidine and introduction of a standardized oral care bundle on IVAC rates and oral health dysfunction scores in mechanically ventilated critically ill adults?

\section{Methods/design \\ Design}

The CHORAL study is a SW-CRT. Each cluster (defined as a single ICU) will be randomly allocated to receive the intervention according to a staggered implementation schedule in one of six sequential steps comprising 2-month intervals. There will be six clusters in total with all clusters commencing with a 2-month control period (baseline) in which standard of care includes chlorhexidine oral care for IVAC prevention. Each cluster will maintain chlorhexidine oral care until they are allocated to crossover from control to intervention according to the randomization schedule. The study completes with a 2-month period during which all clusters have fully deadopted chlorhexidine and implemented the standardized oral care bundle. Total study duration will be 14 months (Fig. 1). We follow CONSORT cluster trial extension guidelines for SW-RCTs in the design of this study [21]. The SPIRIT checklist is provided in Additional file 2 .

The key rationale for our selection of a SW-CRT design includes: (1) avoidance of contamination of the intervention for control participants that is a risk with individual patient randomization; (2) provision of the intervention education at the cluster level; (3) intention to leave the oral care intervention in place at study end; 


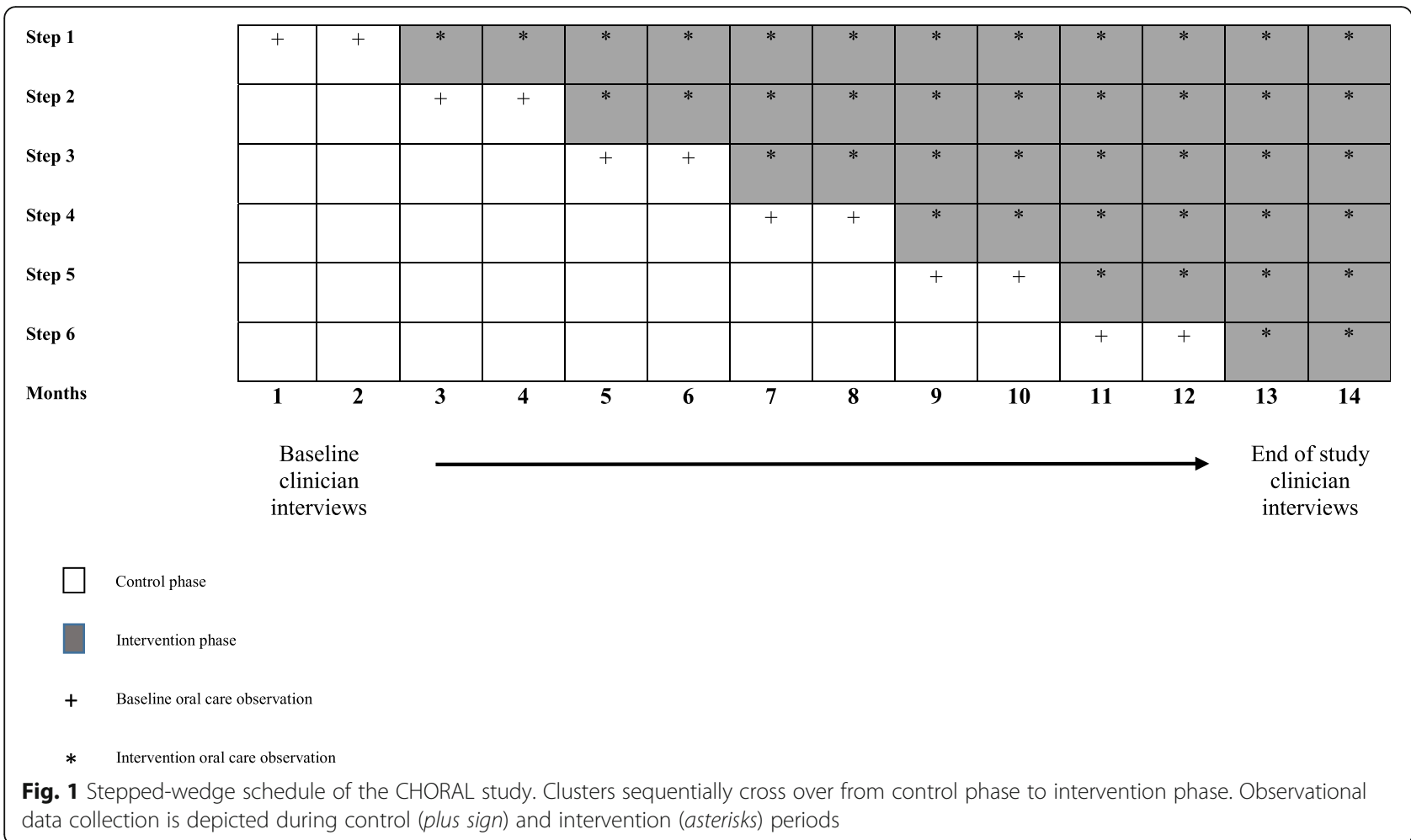

and (4) measurement of outcomes at the level of both clusters and individual patients.

A mixed-methods process evaluation will be conducted as an adjunct to the main trial. Guided by a framework for process evaluation of complex interventions in cluster randomized trials, we will study the processes supporting implementation of our intervention. The objective of our process evaluation is to provide a clear description of implementation processes and to facilitate understanding of the main trial results [22].

\section{Study setting and participants}

The CHORAL study will be conducted in six adult ICUs in five university-affiliated hospitals in Toronto, Canada.

\section{Inclusion and exclusion criteria \\ Unit inclusion for SW-CRT}

We approached units meeting the following criteria for participation: (1) adult ICU capable of providing invasive mechanical ventilation; (2) existing intention to de-adopt oral chlorhexidine prophylaxis; (3) contribution of patient demographic, treatment, and outcome data to the Toronto Intensive Care Observational Registry (iCORE); and (4) admission of at least 50 ventilated patients per month. Exclusion criteria: units not meeting inclusion criteria.

\section{Patient inclusion criteria for SW-CRT}

All adult patients who receive invasive mechanical ventilation in the participating ICUs and are able to receive standardized oral care can be included. For mortality and IVAC rates we will exclude those patients who start in the control group and cross-over to the intervention group.

\section{Randomization and allocation concealment}

Randomization of ICUs to the six sequential steps will be computer-generated by the study statistician. Each ICU will be randomly allocated to start the study intervention according to the randomized staggered implementation schedule and the sequence will be concealed until interventions are assigned. Clusters agreed to participate with the understanding that order of allocation to the intervention would be unknown in advance of randomization. Within control and intervention periods, random dates of observation at each site will be computer generated to collect oral health dysfunction scores and establish intervention fidelity in a subset of patients.

\section{Blinding}

This is a non-blinded study. Clinical and study staff cannot be blinded to study allocation due to the nature of the intervention. Clinical staff in all clusters will be provided with initial education regarding the study intervention and ongoing education to reinforce delivery of 
the standardized oral care bundle. Independent iCORE assessors of mortality and IVAC outcome data will be blinded.

\section{Pre-intervention phase \\ Oral care observations}

In the 2 months preceding de-adoption of chlorhexidine and introduction of a standardized oral care bundle at each site, a trained standardized assessor will use structured observational tools to document baseline oral care delivery, including chlorhexidine concentration and application method [23]. We will document pain presence (yes/no) during oral care using the Critical-Care Pain Observation Tool (CPOT; range $0-8$, score $>2$ indicating pain) [24], and oral health dysfunction using the Beck Oral Assessment Scale (BOAS) [25] on randomly selected dates. The CPOT was recently validated for detecting pain presence in non-verbal ICU patients during oral care delivery and the BOAS tool has been previously validated in the ICU population [26]. For patients able to self-report (mouth words, nod, point), we will also measure symptom intensity using a 0-10 intensityrating scale for (i) oropharyngeal dryness and (ii) procedural oral pain [27] immediately following the oral care delivery. We aim to observe a minimum of 25 patients in each ICU during this baseline phase (150 total).

\section{Intervention phase}

Four weeks prior to the intervention phase, an investigator or designate will deliver intensive education targeting clinician knowledge, attitudes, and behaviors regarding the new oral care intervention to ICU cluster leads using a train-the-trainer model [28]. Cluster leads will comprise an ICU physician-nurse (or physician-pharmacist) dyad supported by unit-level oral care nurse champions. We will utilize an integrated knowledge translation (iKT) approach to facilitate practice change, including an iKT oral care tool kit supporting our oral care intervention [29] comprising a detailed oral care protocol (Table 1), touchpoint video (an edited video of ICU patient experiences and recommendations for oral care), and expert video instruction on oral care delivery (Additional file 1). To minimize bias, cluster leads will distribute the iKT oral care tool kit to frontline ICU nursing and allied health staff 2 weeks prior to the intervention phase.

Table 1 Oral care bundle

\begin{tabular}{|c|c|c|}
\hline $\begin{array}{l}\text { Comprehensive oral care } \\
\text { Q12 hours }\end{array}$ & Equipment & Procedure \\
\hline 1. Oral assessment & $\begin{array}{l}\text {-Flashlight } \\
\text {-Tongue depressor } \\
\text { - Gloves } \\
\text { •Face shield }\end{array}$ & $\begin{array}{l}\text { - Explain procedure to patient } \\
\text { - Gently open mouth or use mouth prop } \\
\text {-Inquire about mouth/throat pain (0-10 NRS) } \\
\text { - Use CPOT tool to evaluate pain in non-verbal pt. } \\
\text { - Treat pain prior to proceeding }\end{array}$ \\
\hline 2. Tooth brushing & $\begin{array}{l}\text {-Yankauer } \\
\text {-12 or } 14 \text { French flexible catheter } \\
\text {-Small soft-bristle or suction } \\
\text { toothbrush } \\
\text {-Sponge swabs } \\
\text {-Sterile water } \\
\text { - Gloves } \\
\text { - Face shield }\end{array}$ & $\begin{array}{l}\text { - Explain procedure to patient } \\
\text { - Perform hand hygiene } \\
\text { - Elevate HOB } 30-45 \text { degrees as tolerated } \\
\text { - Use oral prop to open mouth as needed } \\
\text { - Oral suction with Yankauer or sterile flexible catheter to remove secretions that } \\
\text { may migrate down airway } \\
\text { - Moisten toothbrush with sterile water } \\
\text { - Connect suction toothbrush to continuous suction if applicable } \\
\text { - Brush accessible teeth and gums for } 2 \text { full minutes or } 30 \text { s per quadrant; brush in } \\
\text { one continuous line LUQ }>\text { RUQ }>\text { RLQ }>\text { LLQ } \\
\text { - Gently brush tongue }\end{array}$ \\
\hline $\begin{array}{l}\text { 3. Mouth and lip } \\
\text { moisturizer }\end{array}$ & $\begin{array}{l}\text {-Swabs } \\
\text { - Mouth moisturizer/saliva } \\
\text { replacement or sterile water } \\
\text { - Gloves } \\
\text { - Face shield }\end{array}$ & $\begin{array}{l}\text { - Explain procedure to patient } \\
\text { - Use oral prop to open mouth as needed } \\
\text { - Use } 1-3 \text { swabs to apply moisturizer to oral mucosa, tongue, and lips }\end{array}$ \\
\hline 4. Deep oral suctioning & $\begin{array}{l}\text {-Yankauer or flexible catheter } \\
\text { - Gloves } \\
\text { •Face shield }\end{array}$ & $\begin{array}{l}\text {-Explain procedure to patient } \\
\text { - Use oral prop to open mouth as needed } \\
\text {-Deep oropharyngeal suction (above the cuff) to remove pooled secretions }\end{array}$ \\
\hline $\begin{array}{l}\text { Maintenance oral care Q4 } \\
\text { hours and PRN }\end{array}$ & Equipment & Procedure \\
\hline Mouth and lip moisturizer & -As above & -As above \\
\hline Oral secretion removal & -As above & -As above \\
\hline
\end{tabular}


The following oral care interventions will commence in the intervention phase for each step and become standard of care:

1. Intervention 1 (oral chlorhexidine de-adoption): Each cluster will de-adopt oral chlorhexidine from routine practice for all invasively ventilated patients. Use of routine oral chlorhexidine will not be permitted during the intervention period with the exception of patients prescribed chlorhexidine for non-standard care.

2. Intervention 2 (oral care protocol): This two-part, nurse-led intervention incorporates comprehensive and maintenance oral care activities. Comprehensive care involves twice daily (morning and evening) a) oral assessment (inspection of the oral space, teeth and gums); b) tooth brushing; c) oral/lip moisturization; and d) suctioning oropharyngeal secretions above the cuff. Maintenance care involves, at a minimum of every $4 \mathrm{~h}$ and as needed, a) oral/ lip moisturization; and b) suctioning oropharyngeal secretions above the cuff (Table 1).

One month after allocation to the intervention, a trained assessor will begin to observe fidelity of delivery of the oral care protocol and assess patient oral health status using the BOAS, CPOT, and patient self-report of oral health symptom intensity on randomly selected dates. We will provide each cluster lead with written feedback on these observations for dissemination to frontline ICU staff. For sites identified as having low intervention fidelity during audits $(<70 \%$ compliance across all bundle components), we will provide additional education and intensified audit frequency. We estimate observing a minimum of 25 patients in each ICU during the intervention phase (150 total).

\section{Outcome measures}

The primary outcome is ICU mortality measured at the level of the patient. Secondary outcomes include: (1) IVAC rates; (2) and oral care dysfunction (BOAS) scores measured at the patient level.

\section{Data collection}

iCORE is a local clinical registry that collects deidentified patient demographic and clinical data, including severity of illness, antibiotic usage, IVAC rates, and patient outcomes. We will use the iCORE registry to collect patient demographic and treatment characteristics (i.e., age, sex, co-morbidity, admission diagnosis, nature of admission (elective or emergent), and severity of illness (APACHE III score), as well as to determine outcome data including IVAC rates and ICU mortality. The
BOAS tool [25], oral care delivery compliance, pain, and other oral symptoms will be prospectively measured by the investigator team.

\section{Sample size \\ Mortality}

Recent systematic reviews [30] show that chlorhexidine increased mortality with an odds ratio (OR) of 1.25 (95\% confidence interval (CI) 1.05-1.50). This corresponds to a risk ratio of 1.18 (95\% CI 1.04-1.33) and an absolute reduction in mortality of $5 \%$ (95\% CI $1 \%-6 \%)$. Six clusters averaging 50 ventilated patients per month for 14 months for a total of 4200 patients, assuming an intracluster correlation (ICC) of 0.001 , provides about $80 \%$ power to detect an absolute reduction in mortality of $5.5 \%$ from a baseline rate of $26 \%[6,31,32]$.

\section{Oral health dysfunction}

The BOAS scale ranges from 5 to 20, with a score of 5 equivalent to no oral problems and 20 equivalent to the worst possible oral health state. Previous ICU studies report a mean (standard deviation) score of 10 (2) [26]. Taking into account clustering $(\mathrm{DEF}=1+(\mathrm{n}-1) \times \mathrm{ICC}$ with an $\mathrm{ICC}=0.05$ to 0.2 ), the design effect would range from 3.5 to 10 and therefore the sample size ranges from 86 to 300 . We will observe a minimum of 25 patients per ICU at control and intervention phases. With 150 patients in each time period we have $80 \%$ power to detect a two-point decrease in the BOAS in the intervention group.

\section{Analysis and evaluation Statistical analysis}

We will describe our patient cohort and treatment characteristics using means and standard deviations or medians and interquartile ranges dependent on data distribution for continuous variables and frequencies and percentages for categorical variables. To account for clustering of patients within sites, the primary outcome, mortality, will be analyzed using a generalized linear mixed model (with logit link and binary distribution) adjusting for time to account for secular trends as well as important prognostic factors such as age, sex, APACHE III score, and comorbidities. We will inspect missing data and if less than $5 \%$ are missing we will use imputation by the median values for the continuous variables and mode for the categorical ones. If more than $5 \%$ of the sample has missing values we will use multiple imputations. Differences between the control and intervention periods and time trends will be estimated using OR and their 95\% CIs. IVAC counts with offset number of ventilator days per patient will be analyzed using a generalized linear mixed model with log link and Poisson or negative binomial distribution as dictated by the 
distribution of the data. For mortality and IVAC rates we will exclude those patients who start in the control group and cross-over to the intervention group. BOAS will be summarized using mean and standard deviation and analyzed using linear mixed models (adjusting for clustering of patients within sites) with treatment phase as an independent variable. We will report the CPOT (oral pain during care delivery) scores, and patient selfreport (pain, dryness) outcomes, as medians and IQR and analyze using the Wilcoxon rank sum test to compare the pre-intervention and intervention groups.

\section{Process evaluation}

Our embedded mixed methods process evaluation will examine the reach of oral care intervention education, stakeholder response to chlorhexidine de-adoption and implementation of a standardized oral care bundle, and fidelity of oral care processes [22].

\section{Pre-and post-intervention oral care fidelity}

In the 2 months preceding chlorhexidine de-adoption and implementation of a standardized oral care bundle, and then each month following implementation, trained study team members will collect oral care fidelity data using a structured observational tool on randomized dates. We will observe a minimum of 25 patients per ICU at pre-intervention and intervention phases for a total of 150 patients in each time period. We will report oral care fidelity as medians and IQR and analyze using the Wilcoxon rank sum test to compare the preintervention and intervention groups.

\section{Pre-and post-intervention qualitative interviews}

During pre-intervention and end-of-study periods, we will recruit and interview eligible (i.e., working in a participating unit for $\geq 3$ months) ICU nurses, respiratory therapists, pharmacists, physiotherapists, speech-language pathologists, and physicians. Pre-intervention interviews will target current oral care practices in addition to anticipated barriers and facilitators to the de-adoption of chlorhexidine and implementation of a standardized oral care bundle. End-of-study interviews will address the reach of the educational delivery, stakeholder response to the intervention, perceptions of oral care bundle fidelity, and contextual factors (e.g., secular trends) impacting the study. Sixty clinician interviews (ten per site) in each time period will occur by telephone or in person at the hospital, based on participant preference. We will use qualitative content analysis (CA), a method for describing the content of communication in an objective and systematic manner for transcribed clinician interviews [33]. Two investigators will independently code interviews to enhance rigor.

\section{Discussion}

To our knowledge, the CHORAL study is the first SW-CRT designed to evaluate the effect of de-adopting chlorhexidine oral rinse and implementation of a standardized oral care bundle on ICU mortality, IVACs, and oral health status. In response to multiple independent meta-analyses suggesting the possibility of harm, we aim to conduct a large prospective trial with sufficient statistical power to detect mortality differences between patients receiving chlorhexidine oral care and those receiving non-chlorhexidine oral care. The prospective nature of the trial is important as the mortality signal of concern is only present in meta-analyses $[10,11]$.

Clear evidence regarding the effect of oral chlorhexidine de-adoption on our primary outcome of mortality will clarify concerns of preventable harm. Secondary outcomes, including IVAC rates and oral health status following the de-adoption of oral chlorhexidine and delivery of a standardized oral care bundle, will enhance knowledge regarding the impact of our intervention on patient-centered outcomes, including infection and oral health dysfunction. As chlorhexidine is presently identified as an indicator of high-quality ICU care [6], our study results will prompt re-examination of professional society guidelines.

We have chosen a SW-CRT design due to the expressed desire of participating clusters to de-adopt chlorhexidine and the requirement to deliver the intervention and measure outcomes at the level of individual patients and at the level of the cluster. The CHORAL study introduces a substantial change in longstanding oral care practices which requires provision of education to large groups of care providers across discrete units. An important advantage of the study design is the ability to deliver education in smaller groups (clusters) at pre-defined time-points. This approach will avoid contamination between intervention and control groups seen in parallel randomized controlled trial (RCT) design and alleviate ethical concerns about withholding or blinding of interventions in RCTs.

As effective methods to de-adopt established ICU practices are unclear, our process evaluation will provide clinicians and policy makers with vital information about how the intervention was actively delivered [18]. This is important as ambiguity regarding the composition and delivery of ICU processes threatens interpretation, replication, and research investment. In addition, our embedded process evaluation will clarify helpful strategies for effective education, thereby supporting future integration of oral care interventions across varying practice contexts [29].

\section{Trial status}

Protocol version 14/Aug/2017 commenced on January 31, 2018 and will proceed until March 31, 2019. 


\section{Additional files}

Additional file 1: CHORAL educational videos. (DOCX $13 \mathrm{~kb}$ )

Additional file 2: SPIRIT 2013 Checklist: Recommended items to address in a clinical trial protocol and related documents*. (DOCX $39 \mathrm{~kb}$ )

\section{Abbreviations}

BOAS: Beck Oral Assessment Scale; CA: Content analysis; CDC: Centers for Disease Control; Cl: Confidence interval; CPOT: Critical-Care Pain Observation Tool; CTO: Clinical Trials Ontario; iCORE: Intensive Care Observational Registry; ICU: Intensive care unit; iKT: Integrated knowledge translation; IQR: Interquartile range; IVAC: Infection-related ventilator-associated complications; SW-CRT: Stepped-wedge cluster randomized controlled trial; VAP: Ventilator-associated pneumonia

\section{Acknowledgements}

We acknowledge the important contributions of our research assistants: Teresa Valenzano, Julie Moore, and Tiffany Jefkins. In addition, we thank our patient-family partners and staff in each participating ICU for their assistance with the development of our educational intervention.

\section{Authors' contributions}

$L R, C D, D S, A A$, and $B C$ led the conception and design of the study. $C D, O S$ $L B, E F, V M$, and $B C$ are site investigators and will lead data collection. RP is the statistician for the study. CD wrote this manuscript and approved the final version for publication. All authors have reviewed drafts of the manuscript and given final approval.

\section{Funding}

This study is funded by the Network of Canadian Oral Health Researchers (http://ncohr-rcrsb.ca/page.asp? ID = 111) and the Canadian Lung Association. The funders have not played a role in the design, conduct, or analysis of the study. Dr. Dale is supported by a Canadian Institutes of Health Research (CIHR) Embedded Clinician Researcher Salary Award and the University of Toronto Centre for the Study of Pain (UTCSP).

\section{Availability of data and materials}

The datasets generated during the course of this study may be made available through the corresponding author upon reasonable request.

\section{Ethics approval and consent to participate}

This study was submitted for ethics review through the Clinical Trials Ontario Streamlined Ethics Review System (CTO) and the REB of Record, Sunnybrook Health Sciences Centre Research Ethics Board, granted approval (project ID 0913) on October 25, 2017. Consent is waived for obtaining individual patient consent for oral care and observations of oral care delivery. Patients and families will be notified of the intervention through unit postings, letters, and verbal notification. Written informed consent will be obtained from clinicians prior to participating in baseline and end-of-study interviews. The Toronto Intensive Care Observational Registry (iCORE) is approved by the REB of Record, Sunnybrook Health Sciences Centre Research Ethics Board (project ID 207-2018). All study data will be de-identified for analysis and reporting.

\section{Consent for publication}

No personal identifying information will be collected from participants. Audio recordings and transcripts of clinicians who participated in interviews will be de-identified.

\section{Competing interests}

The authors declare that they have no competing interests.

\section{Author details}

${ }^{1}$ Lawrence S. Bloomberg Faculty of Nursing, University of Toronto, Toronto, Canada. ${ }^{2}$ Trauma, Emergency and Critical Care, Sunnybrook Health Sciences Centre, Toronto, Canada. ${ }^{3}$ Sunnybrook Research Institute, Toronto, Canada. ${ }^{4}$ Department of Critical Care Medicine, Sunnybrook Health Sciences Centre, Toronto, Canada. ${ }^{5}$ Florence Nightingale Faculty of Nursing, Midwifery and Palliative Care, King's College, London, UK. ${ }^{6}$ Department of Critical Care, St. Michael's Hospital, Toronto, Canada. 'Li Ka Shing Knowledge Institute,
Toronto, Canada. ${ }^{8}$ Department of Pharmacy, Mount Sinai Hospital, Toronto, Canada. ${ }^{9}$ Leslie Dan Faculty of Pharmacy, University of Toronto, Toronto, Canada. ${ }^{10}$ Interdepartmental Division of Critical Care Medicine, University of Toronto, Toronto, Canada. ${ }^{11}$ Department of Medicine, University Health Network, Toronto, Canada. ${ }^{12}$ Faculty of Dentistry, University of Toronto, Toronto, Canada. ${ }^{13}$ Department of Dentistry, Sunnybrook Health Sciences Centre, Toronto, Canada.

Received: 12 March 2019 Accepted: 21 August 2019

Published online: 24 October 2019

\section{References}

1. Heyland DK, Cook DJ, Griffith L, Keenan SP, BrunBuisson C. The attributable morbidity and mortality of ventilator-associated pneumonia in the critically ill patient. The Canadian Critical Trials Group. Am J Respir Crit Care Med. 1999;159(4 Pt 1):1249-56.

2. Muscedere J, Dodek P, Keenan S, Fowler R, Cook D, Heyland D, for the VAP Guidelines Committee and the Canadian Critical Care Trials Group. Comprehensive evidence-based clinical practice guidelines for ventilatorassociated pneumonia: Prevention. J Crit Care. 2008:23(1):126-37.

3. Institute for Health Care Improvement. How-to guide: Prevent ventilatorassociated pneumonia. 2012. http://www.ihi.org/resources/Pages/Tools/ HowtoGuidePreventVAP.aspx

4. NICE. Technical patient safety solutions for ventilator-associated pneumonia in adults. NICE. Technical patient safety solutions for ventilator-associated pneumonia in adults. 2008. http://guidance.nice.org.uk/PSG002.

5. Klompas M, Speck K, Howell Greene LR, Berenholtz SM. Reappraisal of routine oral care with chlorhexidine gluconate for patients receiving mechanical ventilation: systematic review and meta-analysis. JAMA Intern Med. 2014;174(5):751-61.

6. Price R, MacLennan G, Glen J, SuDDICU Collaboration. Selective digestive or oropharyngeal decontamination and topical oropharyngeal chlorhexidine for prevention of death in general intensive care: systematic review and network meta-analysis. BMJ. 2014;348:g2197.

7. Bekaert M, Timsit JF, Vansteelandt S, Depuydt P, Vesin A, GarrousteOrgeas M, Decruyenaere J, Clec'h C, Azoulay E, Benoit D, Outcomerea Study G. Attributable mortality of ventilator-associated pneumonia: a reappraisal using causal analysis. Am J Respir Crit Care Med. 2011;184(10):1133-9.

8. Houston S, Hougland P, Anderson JJ, LaRocco M, Kennedy V, Gentry LO. Effectiveness of $0.12 \%$ chlorhexidine gluconate oral rinse in reducing prevalence of nosocomial pneumonia in patients undergoing heart surgery. Am J Crit Care. 2002;11:567+

9. Segers P, Speekenbrink RG, Ubbink DT, van Ogtrop ML, de Mol BA. Prevention of nosocomial infection in cardiac surgery by decontamination of the nasopharynx and oropharynx with chlorhexidine gluconate: a randomized controlled trial. JAMA. 2006;296(20):2460-6.

10. Fourrier F, Cau-Pottier E, Boutigny $H$, Roussel-Delvallez $M$, Jourdain $M$, Chopin C. Effects of dental plaque antiseptic decontamination on bacterial colonization and nosocomial infections in critically ill patients. Intensive Care Med. 2000;26(9):1239-47.

11. Scannapieco FA, Yu J, Raghavendran K, Vacanti A, Owens SI, Wood K, Mylotte JM. A randomized trial of chlorhexidine gluconate on oral bacterial pathogens in mechanically ventilated patients. Crit Care. 2009;13(4):R117.

12. Plantinga N, Wittekamp B, Leleu K, Depuydt P, Abeele A, Brun-Buisson C, Bonten M. Oral mucosal adverse events with chlorhexidine $2 \%$ mouthwash in ICU. Intensive Care Med. 2016;42(4):620-1

13. Kempen PM. A tale of silent aspiration: Are guidelines good for every patient? Anesth Analg. 2015;121(3):829-31.

14. Adhikari NKJ, Fowler RA, Bhagwanjee S, Rubenfeld GD. Critical care and the global burden of critical illness in adults. Lancet. 2010;376(9749):1339-46.

15. Sands KM, Wilson MJ, Lewis MAO, Wise MP, Palmer N, Hayes AJ, Barnes RA, Williams DW. Respiratory pathogen colonization of dental plaque, the lower airways, and endotracheal tube biofilms during mechanical ventilation. J Crit Care. 2017;37:30-7.

16. Dennesen $P$, van der Ven A, Vlasveld M, Lokker L. Inadequate salivary flow and poor oral mucosal status in intubated intensive care unit patients. Crit Care Med. 2003;31:781-6.

17. Muscedere J, Sinuff T, Heyland DK, Dodek PM, Keenan SP, Wood G, Jiang X, Day AG, Laporta D, Klompas M. The clinical impact and preventability of ventilator-associated conditions in critically ill patients who are mechanically ventilated. Chest. 2013;144(5):1453-60. 
18. Campbell GB, Happ MB. Symptom identification in the chronically critically ill. AACN Adv Crit Care. 2010;21(1):64-79.

19. Puntillo K, Arai S, Cooper B, Stotts N, Nelson J. A randomized clinical trial of an intervention to relieve thirst and dry mouth in intensive care unit patients. Intensive Care Med. 2014;40(9):1295-302.

20. Niven DJ, Mrklas KJ, Holodinsky JK, Straus SE, Hemmelgarn BR, Jeffs LP Stelfox HT. Towards understanding the de-adoption of low-value clinical practices: a scoping review. BMC Med. 2015;13:255.

21. Hemming K, Taljaard M, McKenzie JE, Hooper R, Copas A, Thompson JA, DixonWoods M, Aldcroft A, Doussau A, Grayling M, Kristunas C, Goldstein CE, Campbell MK, Girling A, Eldridge S, Campbell MJ, Lilford RJ, Weijer C, Forbes $A B$, Grimshaw JM. Reporting of stepped wedge cluster randomised trials: extension of the CONSORT 2010 statement with explanation and elaboration. BMJ. 2018;363:k1614.

22. Grant A, Treweek S, Dreischulte T, Foy R, Guthrie B. Process evaluations for cluster-randomised trials of complex interventions: a proposed framework for design and reporting. Trials. 2013;14:15.

23. Feider LL, Mitchell P. Validity and reliability of an oral care practice survey for the orally intubated adult critically ill patient. Nurs Res. 2009;58(5):374-7.

24. Gelinas C, Fillion L, Puntillo K, Viens C, Fortier M. Validation of the Critical-Care Pain Observation Tool in adult patients. Am J Crit Care. 2006;15(4):420-7.

25. Beck S. Impact of a systematic oral care protocol on stomatitis after chemotherapy. Cancer Nurs. 1979;2(3):185-200.

26. Ames NJ, Sulima P, Yates JM, McCullagh L, Gollins SL, Soeken K, Wallen GR. Effects of systematic oral care in critically ill patients: A multicenter study. Am J Crit Care. 2011:20(5):e103-14.

27. Barr J, Fraser GL, Puntillo K, Ely EW, Gelinas C, Dasta JF, Davidson JE, Devlin JW, Kress JP, Joffe AM, Coursin DB, Herr DL, Tung A, Robinson BR, Fontaine DK, Ramsay MA, Riker RR, Sessler CN, Pun B, Skrobik Y, Jaeschke R, American College of Critical Care Medicine. Clinical practice guidelines for the management of pain, agitation, and delirium in adult patients in the intensive care unit. Crit Care Med. 2013;41(1):263-306.

28. Grol R, Grimshaw J. From best evidence to best practice: effective implementation of change in patients' care. Lancet. 2003;362(9391):1225-30.

29. Sinuff T, Muscedere J, Adhikari NKJ, Stelfox HT, Dodek P, Heyland DK, Rubenfeld GD, Cook DJ, Pinto R, Manoharan VH, Currie J, Cahill N, Friedrich J, Amaral A, Piquette D, Scales DC, Dhanani S, Garland A, for the KRITICAL Working Group, the Canadian Critical Care Trials Group, and the Canadian Critical Care Society. Knowledge translation interventions for critically ill patients: A systematic review. Crit Care Med. 2013;41(11):2627-40.

30. Price RJ, Cuthbertson BH. on behalf of the SuDDICU: Selective decontamination of the digestive tract and oropharynx: after 30 years of debate is the definitive answer in sight? Curr Opin Crit Care. 2016;22(2):161-6.

31. Hemming K, Girling A, Martin J, Bond SJ. Stepped wedge cluster randomized trials are efficient and provide a method of evaluation without which some interventions would not be evaluated. J Clin Epidemiol. 2013; 66:1058-9.

32. Woertman W, de Hoop E, Moerbeek M, Zuidema SU, Gerritsen DL, Teerenstra S. Stepped wedge designs could reduce the required sample size in cluster randomized trials. J Clin Epidemiol. 2013;66:752-8

33. Vaismoradi $\mathrm{M}$, Turunen $\mathrm{H}$, Bondas $\mathrm{T}$. Content analysis and thematic analysis: Implications for conducting a qualitative descriptive study. Nurs Health Sci. 2013;15(3):398-405.

\section{Publisher's Note}

Springer Nature remains neutral with regard to jurisdictional claims in published maps and institutional affiliations.

Ready to submit your research? Choose BMC and benefit from:
- fast, convenient online submission
- thorough peer review by experienced researchers in your field
- rapid publication on acceptance
- support for research data, including large and complex data types
- gold Open Access which fosters wider collaboration and increased citations
- maximum visibility for your research: over 100M website views per year
At BMC, research is always in progress.
Learn more biomedcentral.com/submissions

